\section{FRI0507 THE RELATIONSHIP BETWEEN 10-YEAR CARDIOVASCULAR RISK SCORES AND DISEASE ACTIVITY IN PATIENTS WITH PSORIATIC ARTHRITIS}

N. Ikumi ${ }^{1}$, F. Farkas ${ }^{1}$, A. Szentpetery ${ }^{1}$, B. Kirby ${ }^{2}$, O. FitzGerald ${ }^{1}$

${ }^{1}$ Rheumatology; ${ }^{2}$ Dermatology, St. Vincent's University Hospital, Dublin, Ireland

Background: Psoriatic arthritis (PsA) is a chronic inflammatory arthritis associated with an increased prevalence of cardiovascular (CV) disease ${ }^{1}$. This increase may in turn be due to a higher prevalence of traditional CV risk factors as well as to persistent inflammatory musculoskeletal and skin disease ${ }^{2}$. Disease activity in PsA may be assessed by the Composite Psoriatic Disease Activity Index (CPDAI) across 5 domains of involvement: peripheral joints, skin, entheses, dactylitis and spinal manifestations. Long-term CV risk is evaluated using several methods for general population

Objectives: (1) To describe CV risk factors and 10-year CV risk scores among patients with PsA; and (2) to correlate with baseline CPDAI in this longitudinal study

Methods: PsA patients fulfilling the CASPAR criteria were enrolled consecutively from Rheumatology clinics. Fasting bloods were obtained for glucose, insulin, lipids. Patients underwent thorough physical examination, joint and skin assessments and completed questionnaires on health, depression/anxiety and quality of life. Four different CV risk scores were calculated: (1) Framingham Coronary risk score (FCS); (2) American College of Cardiology and American Heart Association (ACC/AHA) 10-year atherosclerotic cardiovascular disease (ASCVD) algorithm; (3) Systematic Coronary Risk Evaluation (SCORE) algorithm; and (4) QRISK2 (2016). CPDAI was calculated with CPDAl cutoff $\leq 4$ representing low/minimal disease activity (LDA) or remission. CPDAl $>4$ represented active disease requiring treatment change.

Results: 100 PsA patients were recruited with mean age $52.4( \pm 10.5)$ (male $55 \%)$. Mean disease duration for PsA was $17.9( \pm 10)$ years. 58 patients (age $52.4 \pm 9.6$, male $60.3 \%$ ) had CPDAl $\leq 4$ (LDA Gp) and 41 patients (age $52.4 \pm 11.9$, male $48.8 \%$ ) had CPDAl $>4$ (active Gp) at baseline. There were significantly more patients with $\mathrm{BMI}>35$ in active $\mathrm{Gp}$, but mean $\mathrm{BMI}$, waist/hip ratio, blood pressure, fasting glucose, insulin, lipids, and patients taking NSIADs, oral corticosteroid, Methotrexate and/or biologics treatment were otherwise similar compared to LDA Gp. Skin (Psoriasis Area Severity Index (PASI); Dermatology Life Assessment Questionnaire (DLQI)) assessments together with levels of inflammatory markers such as C-reactive protein (CRP) were also similar in both groups. More active Gp had enthesitis (58.5\%) and acute dactylitis (14.6\%) $(P<0.01$ and 0.02 , respectively). The mean FCS, ASCVD, SCORE and QRISK2 were similar in both groups $(8.5 \pm 7.1 \%$ vs. $6.2 \pm 6.9 \%, P=0.11 ; 8.9 \pm 8.5 \%$ vs. $7.8 \pm 7.9 \%, P=0.54$; $2.2 \pm 2.6 \%$ vs. $2.0 \pm 2.7 \%, P=0.81 ; 11.2 \pm 9.2 \%$ vs. $11.3 \pm 11 . \%, P=0.97$, LDA Gp and active Gp respectively). Interestingly, there were more smokers in LDA Gp $(60.3 \%$ vs $39.0 \% ; \mathrm{p}=0.04$ ) and this likely accounts for the higher number of LDA Gp patients with $\mathrm{FCS}>10 \%$.

Conclusions: We found similar prevalence of traditional CV risk factors and similar 10-year CV risk scores in PsA patients regardless of their CPDAI. Further correlation with measures of disease activity over time will be required. References:

[1] Ogdie A. ARD 2015.

[2] Eder L. ARD 2016.

Disclosure of Interest: N. Ikumi: None declared, F. Farkas: None declared, A. Szentpetery: None declared, B. Kirby Grant/research support from: abbie, O. FitzGerald Grant/research support from: abbie, Pfizer, BMS, Consultant for: abbie, Pfizer, BMS, Celgene, Janssen, Novartis, UCB, Eli Lilly

DOI: 10.1136/annrheumdis-2017-eular.4798

\section{FRI0508 THE EFFECT OF CERTOLIZUMAB PEGOL ON EXTRA-ARTICULAR MANIFESTATIONS OF PSORIATIC ARTHRITIS OVER 4 YEARS OF TREATMENT IN PATIENTS WITH AND WITHOUT PRIOR ANTI-TNF EXPOSURE}

O. FitzGerald ${ }^{1}$, R. Fleischmann ${ }^{2}$, A. Kavanaugh ${ }^{3}$, B. Hoepken ${ }^{4}$, L. Peterson ${ }^{5}$, D. Gladman ${ }^{6}{ }^{1}$ St. Vincent's University Hospital and Conway Institute for Biomolecular Research, University College Dublin, Dublin, Ireland: ${ }^{2}$ UT Southwestern Medical Center and Dallas Metroplex Clinical Research Center, Dallas; ${ }^{3}$ UC San Diego School of Medicine, la Jolla, United States; ${ }^{4}$ UCB Pharma, Monheim, Germany; ${ }^{5}$ UCB Pharma, Raleigh, United States; ${ }^{6}$ Krembil Research Institute, Toronto Western Hospital, Toronto, Canada

Background: Extra-articular manifestations (EAMs) of psoriatic arthritis (PSA) include nail psoriasis, dactylitis, and enthesitis, which can significantly impact patients' (pts') quality of life. ${ }^{1}$ In the RAPID-PsA trial (NCT01087788), certolizumab pegol (CZP) improved the signs and symptoms of EAMs in pts with PsA over 96 weeks (wks) ${ }^{2}$

Objectives: To report improvements in EAMs of PsA in pts treated with CZP over 4 years, both with and without prior anti-TNF exposure.

Methods: The RAPID-PsA trial was double-blind and placebo-controlled to Wk24, dose-blind to Wk48, and open-label (OL) to Wk216. Pts had active PsA and had failed $\geq 1$ DMARD. Pts originally randomized to CZP (200mg Q2W or $400 \mathrm{mg}$ Q4W, following 400mg loading dose at Wks $0,2,4)$ continued their assigned dose in the OL period. We present EAM data for those pts originally randomized to $\mathrm{CZP}$, with involvement of the particular EAM at baseline (BL), and both with and without prior anti-TNF exposure. EAMs assessed include nail psoriasis (modified Nail Psoriasis Severity Index [mNAPSI], BL involvement $=\mathrm{BL}$ mNAPSI $>0$ ), enthesitis (Leeds Enthesitis Index [LEI], BL involvement $=\mathrm{BL}$ LEI $>0$ ), and dactylitis (Leeds Dactylitis Index [LDI], BL involvement $=\geq 1$ digit affected with a difference in circumference $\geq 10 \%$ compared to the opposite digit). Also presented are the proportions of pts with BL involvement of each EAM who achieved total resolution of the respective EAM on follow-up (a score of 0 for mNAPSI, LEI, or LDI). Observed values are reported, combined for pts receiving either CZP dose regimen.

Results: A total of 409 PsA pts were randomized; 273 received CZP from Wk0. Among CZP-randomized pts, 197 had nail psoriasis at BL (159 without, and 38 with, prior anti-TNF exposure), 172 had enthesitis (133 without, and 39 with, prior anti-TNF exposure), and 73 had dactylitis (56 without, and 17 with, prior anti-TNF exposure). Although relatively few pts were anti-TNF experienced, a large proportion of pts both with and without prior anti-TNF exposure with BL involvement went on to achieve total resolution of the respective EAM following 48 wks of CZP treatment (Table). Among pts completing the study, the proportions achieving total resolution were maintained or further increased from Wk48 to Wk216 (Table). Mean scores of all EAMs assessed showed improvements by Wk48 of CZP treatment in pts both with and without prior anti-TNF exposure, which were maintained to Wk216 in pts completing the study (Table).

Table: Improvements in extra-articular manifestations of PsA over 216 weeks of CZP treatment in patients with and without prior anti-TNF exposure (observed values)

\begin{tabular}{|c|c|c|c|c|}
\hline & \multicolumn{4}{|c|}{ Week 0 CZP dose combined ( $N=273$ ) } \\
\hline & Baseline & Week 48 & Week 96 & Week 216 \\
\hline \multicolumn{5}{|c|}{$\begin{array}{l}\text { Number of patients observed } \\
\text { Mean score (standard deviation) } \\
\text { Patients with total resolution, } n \text { (\%) }\end{array}$} \\
\hline \multicolumn{5}{|l|}{ Nail psoriasis (mNAPSI) [a] } \\
\hline Anti-TNF naïve $(n=159)$ & $\begin{array}{c}159 \\
3.4(2.1) \\
-\end{array}$ & $\begin{array}{c}139 \\
1.1(1.5) \\
71(51.1)\end{array}$ & $\begin{array}{c}129 \\
0.7(1.3) \\
84(65.1)\end{array}$ & $\begin{array}{c}109 \\
0.4(0.8) \\
80(73.4)\end{array}$ \\
\hline Anti-TNF experienced $(n=38)$ & $\begin{array}{c}38 \\
2.9(1.8) \\
-\end{array}$ & $\begin{array}{c}33 \\
0.9(2.1) \\
22(66.7)\end{array}$ & $\begin{array}{c}29 \\
0.6(1.1) \\
19(65.5)\end{array}$ & $\begin{array}{c}23 \\
0.5(0.7) \\
14(60.9)\end{array}$ \\
\hline \multicolumn{5}{|l|}{ Enthesitis (LEI) [b] } \\
\hline Anti-TNF naïve $(n=133)$ & $\begin{array}{c}133 \\
3.0(1.7) \\
-\end{array}$ & $\begin{array}{c}116 \\
0.8(1.5) \\
83(71.6)\end{array}$ & $\begin{array}{c}104 \\
0.7(1.3) \\
74(71.2)\end{array}$ & $\begin{array}{c}85 \\
0.5(1.0) \\
65(76.5)\end{array}$ \\
\hline Anti-TNF experienced ( $n=39)$ & $\begin{array}{c}39 \\
2.9(1.6) \\
-\end{array}$ & $\begin{array}{c}33 \\
1.2(2.1) \\
23(69.7)\end{array}$ & $\begin{array}{c}27 \\
0.8(1.4) \\
19(70.4)\end{array}$ & $\begin{array}{c}25 \\
0.5(1.2) \\
20(80.0)\end{array}$ \\
\hline \multicolumn{5}{|l|}{ Dactylitis (LDI) [c] } \\
\hline Anti-TNF naïve $(n=56)$ & $\begin{array}{c}56 \\
50.9(64.7) \\
-\end{array}$ & $\begin{array}{c}48 \\
0.0(0.0) \\
44(91.7)\end{array}$ & $\begin{array}{c}46 \\
0.0(0.0) \\
42(91.3)\end{array}$ & $\begin{array}{c}41 \\
0.3(2.1) \\
38(92.7)\end{array}$ \\
\hline Anti-TNF experienced ( $n=17)$ & $\begin{array}{c}17 \\
52.5(42.7) \\
-\end{array}$ & $\begin{array}{c}14 \\
12.6(25.3) \\
11(78.6)\end{array}$ & $\begin{array}{c}11 \\
0.0(0.0) \\
9(81.8)\end{array}$ & $\begin{array}{c}9 \\
4.2(12.7) \\
8(88.9)\end{array}$ \\
\hline
\end{tabular}

Conclusions: PSA patients treated with CZP for up to 4 years, both with and without prior anti-TNF exposure, exhibited sustained improvements in the extra-articular manifestations of PsA.

References:

[1] Ritchlin C. Ann Rheum Dis 2009;68:1387-94.

[2] FitzGerald O. Ann Rheum Dis 2015;74(2):349.

Acknowledgements: This study was funded by UCB Pharma. We thank the patients and their caregivers in addition to the investigators and their teams who contributed to this study. Editorial services were provided by Costello Medical Consulting.

Disclosure of Interest: O. FitzGerald Grant/research support from: AbbVie, Bristol Myers Squibb, Janssen, Novartis, Pfizer, Consultant for: AbbVie, Celgene, Janssen, Pfizer, Roche, UCB Pharma, Speakers bureau: AbbVie, Celgene, Janssen, Pfizer and UCB Pharma, R. Fleischmann Grant/research support from: Abbott, Amgen, AstraZeneca, Bristol-Myers Squibb, Eli Lilly, Genentech, Janssen, MSD Pharmaceuticals, Novartis, Pfizer, Roche, Sanofi-Aventis, UCB Pharma, Consultant for: AbbVie, Amgen, AstraZeneca, Bristol-Myers Squibb, Celgene, Genentech, GlaxoSmithKline, Janssen, Eli Lilly, Pfizer, Sanofi-Aventis, UCB Pharma, A. Kavanaugh Grant/research support from: Abbott, Amgen, BristolMyers Squibb, Janssen, Pfizer, Roche, UCB Pharma, B. Hoepken Employee of: UCB Pharma, L. Peterson Employee of: UCB Pharma, D. Gladman Grant/research support from: Abbott, Bristol-Myers Squibb, Celgene, Johnson \& Johnson, MSD Pharmaceuticals, Novartis, Pfizer, and UCB Pharma, Consultant for: Abbott, Bristol-Myers Squibb, Celgene, Johnson \& Johnson, MSD Pharmaceuticals, Novartis, Pfizer, and UCB Pharma

DOI: 10.1136/annrheumdis-2017-eular.1969 